\title{
Malignant Solitary Fibrous Kidney Tumor with Peritoneal Disease: A Case Report
}

\author{
Maria Isabel Rodríguez $\mathrm{Cruz}^{\mathrm{a}} \quad J o s e$ Emilio Hernández Sánchez ${ }^{\mathrm{a}}$ \\ Beatriz Segovia Blázquez ${ }^{\mathrm{b}}$ Sara Belen Prieto Nogal ${ }^{a}$ \\ Luis Miguel Gómez Tejedaa \\ Departments of ${ }^{\mathrm{a} U}$ rology and ${ }^{\mathrm{b}}$ Pathology, Hospital Nuestra Señora de Sonsoles, \\ Ávila, Spain
}

\section{Key Words}

Solitary fibrous tumor $\cdot$ Kidney $\cdot$ Peritoneal disease

\section{Abstract}

We report a case of a large malignant solitary fibrous kidney tumor. A complete surgical resection of the primary tumor and peritoneal disease was carried out, and a histological examination confirmed the initial diagnosis. We describe and discuss the characteristics of this rare kidney neoplasm.

(C) 2014 S. Karger AG, Basel

\section{Introduction}

Solitary fibrous tumor occurs mainly in the pleural cavity $[1,2]$. The occurence in the kidney and other locations is uncommon $[3,4]$. Most of the reported cases are histologically benign; there are fewer cases of malignant fibrous tumors. Malignant solitary fibrous tumor is a rare neoplasm, which includes therapeutic and prognostic specialties.

\section{Case Report}

An 84-year-old woman was admitted to our hospital complaining about a 2-month history of abdominal pain and constipation. Despite symptomatology, she referred with a big abdominal diameter that had increased in the last 2 years. Physical examination revealed a

Dr. Maria Isabel Rodríguez Cruz

Hospital Nuestra Señora de Sonsoles

Vereda de las Mozas 22; $6^{\circ} 4$

ES-05003 Ávila (Spain)

E-Mail doritabsb@hotmail.com 
large palpable abdominal mass. Abdominal ultrasonography and a CT scan showed a large mass arising from the left kidney, occupying the left abdomen and a part of the right abdomen without metastases (fig. 1). The patient underwent left radical nephrectomy and resection of peritoneal implantations, which were observed during surgery (fig. 2). The pathologic diagnosis made was malignant solitary fibrous tumor. Postoperative period passed without incidents. Neither chemotherapy nor radiation therapy was carried out, as decided by an urologist, a pathologist and an oncologist. The patient was asymptomatic at the first follow-up visit. She suffered an early local recurrence with ascites, abdominal pain and peritoneal implantations, as was shown by a CT scan. Because of the patient's advanced age, we opted for a moderate treatment, and she died 3 months after surgery.

\section{Pathological Findings}

The gross specimen included a large tumor of $30.7 \times 22.6 \times 18.5 \mathrm{~cm}$ overall dimension and 5,050 g weight; it was well circumscribed and lobulated. The cut section revealed whitebrown whirled-appearing tissue, with macroscopic necrosis and hemorrhagic areas. Microscopic examination revealed a mesenchymal neoplasm with hyper- and hypocellular areas consisting of spindle cells with elongate, stellate, dense or vesicular nuclei with inconspicuous nucleoli. The cytoplasm was scant, indistinct and palely eosinophilic.

The cells were arranged in short fascicles, storiform with hemangiopericytoma-like patterns and occasionally separated by strip-like bands of collagen. Areas of myxoid stroma were detected as well as focal sheet-like hyalinization and areas of high cellularity showing crowded overlapping nuclei, pleomorphism, nuclear atypia and numerous mitotic figures (7 mitoses/10 high-power fields). Necrosis and hemorrhage were also reported.

Immunohistochemically, the cells were positive for CD34, CD99, Bcl2, vimentin and smooth muscle actin, while negative for desmin and HBM45 (fig. 3).

\section{Discussion}

Solitary fibrous tumor occurs mainly in the pleural cavity $[1,2]$. Other locations, including the kidney, are extremely rare but existing $[3,5]$. Most of these neoplasms are found in adults, but pediatric cases are also reported [6]. Generally, fibrous tumor is a slow-growing neoplasm and its most common location in the kidney is the renal capsule [1].

Clinically, some cases, including the present one, can appear as palpable abdominal mass or intestinal obstruction [7] and begin as abdominal pain or gross hematuria. A CT scan is not able to distinguish between carcinomas or sarcomas, and diagnosis is frequently made postoperatively [4]. Our patient did not consult a doctor despite an increased abdominal perimeter, which was probably the reason why the diagnosis could only be made so late.

Malignant solitary fibrous tumor is usually solitary, varies in size and appears in different cystic areas, with hemorrhage or necrosis present [7]. Microscopically, it is characterized by both hyper- and hypocellularity, and mitotic activity is between 4-10/10 high-power fields [2]. Furthermore, the tumor has a high vascularity with hemangiopericytoma-like patterns.

Immunohistochemical analysis is compulsory to obtain a diagnosis [2]. Most of the cases are positive for $\mathrm{CD} 34$. In addition, Bcl2, CD99 and vimentin are frequently expressed; however, keratin, actin, S100, c-kit and CD31 are usually negative [4]. 
Rodríguez Cruz et al.: Malignant Solitary Fibrous Kidney Tumor with Peritoneal Disease: A Case Report

Habitually, solitary fibrous tumor is benign. Nevertheless, there are 14 malignant cases reported [6]. Indications for malignancy are hypercellularity, cellular pleomorphism and a mitotic rate of more than 4 high-power fields [2]. These features were present in our patient and are described in this case report.

A differential diagnosis must be made between other mesenchymal tumors such as leiomyoma or leiomyosarcoma, sarcomatoid renal tumor and transitional cell carcinoma [3, 7].

There is no standard treatment for malignant solitary fibrous tumor because its occurrence is rare [4]. Radical surgery is considered the first choice of treatment [3]. For incomplete resection, poor prognosis is observed. Some authors suggest radiotherapy or adjuvant chemotherapy, although poor outcomes have been reported for these treatments $[3,4,8]$. In our case, we decided not to opt for adjuvant treatment because the patient was elderly and the literature reports poor outcomes. When local recurrence occurred, it was too late for treatment.

In conclusion, the diagnosis must be established as soon as possible; metastasis in patients with a delayed diagnosis leads to poor prognosis and worse surveillance. Fibrous kidney tumor is rare, and we need more patients to include in trials for adjuvant therapy.

\section{References}

1 Fine SW, McCarthy DM, Chan TY, Epstein JI, Argani P: Malignant solitary fibrous tumor of the kidney: report of a case and comprehensive review of the literature. Arch Pathol Lab Med 2006;130:857-861.

2 Robinson LA: Solitary fibrous tumor of the pleura. Cancer Control 2006;13:264-269.

-3 Zhao G, Li G, Han R: Two malignant solitary fibrous tumors in one kidney: case report and review of the literature. Oncol Lett 2012;4:993-995.

4 Sfoungaristos S, Papatheodorou M, Kavouras A, Perimenis P: Solitary fibrous tumor of the kidney with massive retroperitoneal recurrence. A case presentation. Prague Med Rep 2012;113:246-250.

-5 Llarena Ibarguren R, Eizaguirre Zarzai B, Lecumberri Castaños D, Padilla Nieva J, Crespo Atín V, Martín Bazaco J, Azurmendi Sastre V, Pertusa Peña C: Bilateral renal solitary fibrous tumor (in Spanish). Arch Esp Urol 2003;56:835-840.

6 Wu WW, Chu JT, Romansky SG, Shane L: Pediatric renal solitary fibrous tumor: report of a rare case and review of the literature. Int J Surg Pathol 2013, E-pub ahead of print.

7 Khater N, Khauli R, Shahait M, Degheili J, Khalifeh I, Aoun J: Solitary fibrous tumors of the kidneys: presentation, evaluation, and treatment. Urol Int 2013;91:373-383.

8 Cuello J, Brugés R: Malignant solitary fibrous tumor of the kidney: report of the first casa managed with interferon. Case Rep Oncol Med 2013, E-pub ahead of print. 
Case Reports in

Nephrology and
Urology
Case Rep Nephrol Urol 2014;4:70-74

DOI: 10.1159/000362539

Rodríguez Cruz et al: Malignant Solitary Fibrous Kidney Tumor with Peritoneal Disease: A Case Report
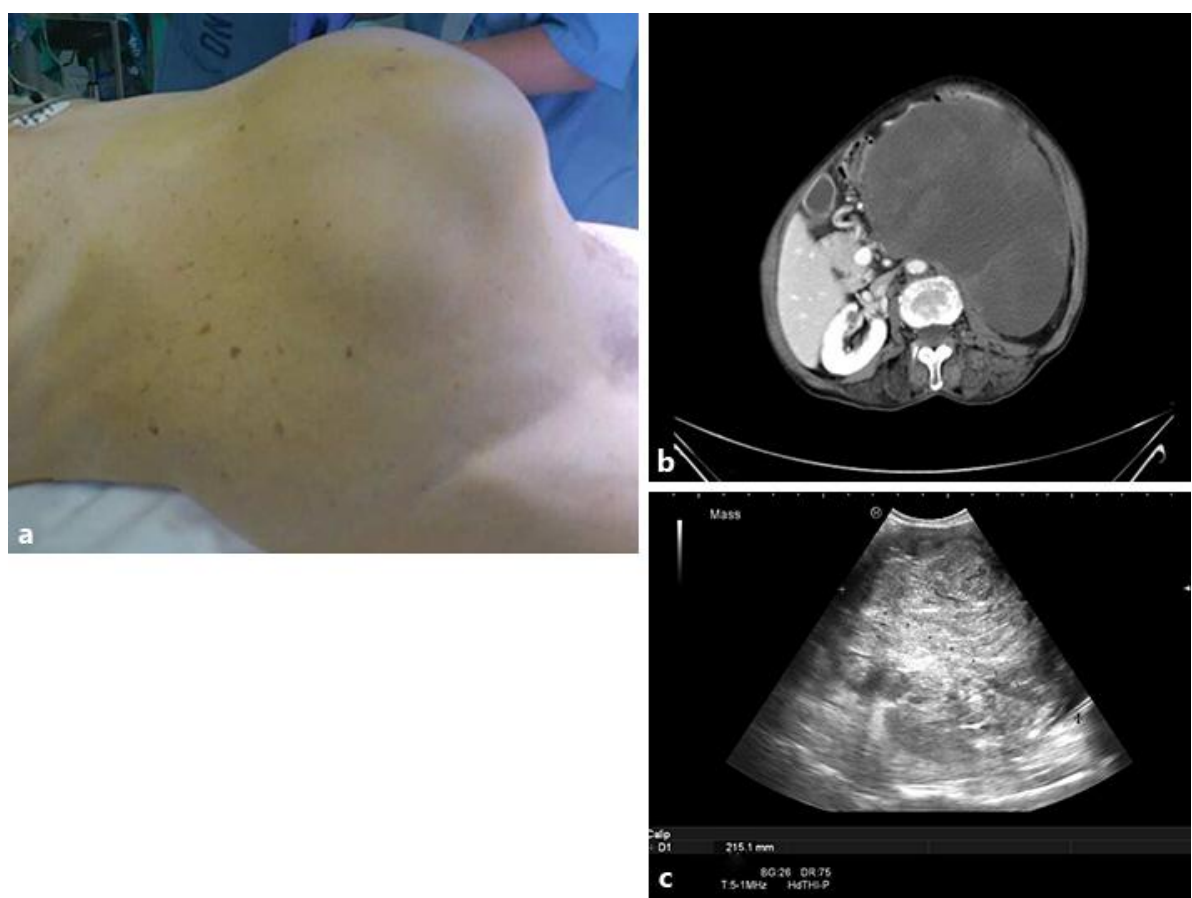

Fig. 1. a Abdominal mass. b CT scan with a great mass arising from the left kidney. c Renal mass as showed by ultrasonography.
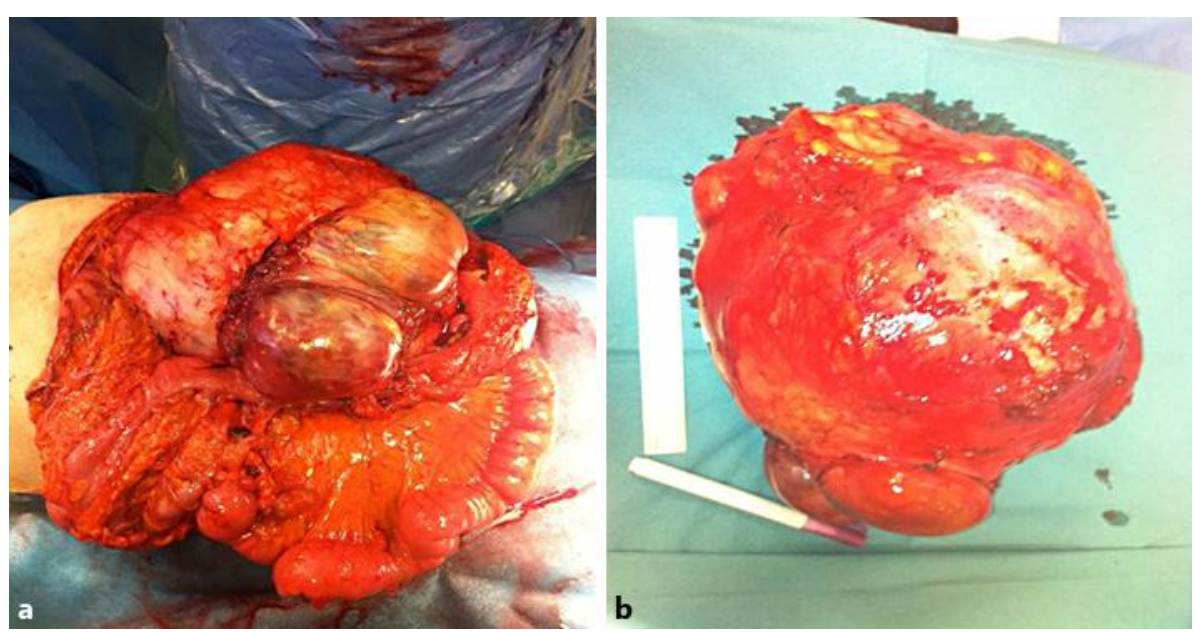

Fig. 2. a Intraoperative mass. b Macroscopic tumor after surgical resection. 


\section{Case Reports in \\ Nephrology and Urology}

Case Rep Nephrol Urol 2014;4:70-74 DOI: $10.1159 / 000362539$

Rodríguez Cruz et al.: Malignant Solitary Fibrous Kidney Tumor with Peritoneal Disease: A Case Report
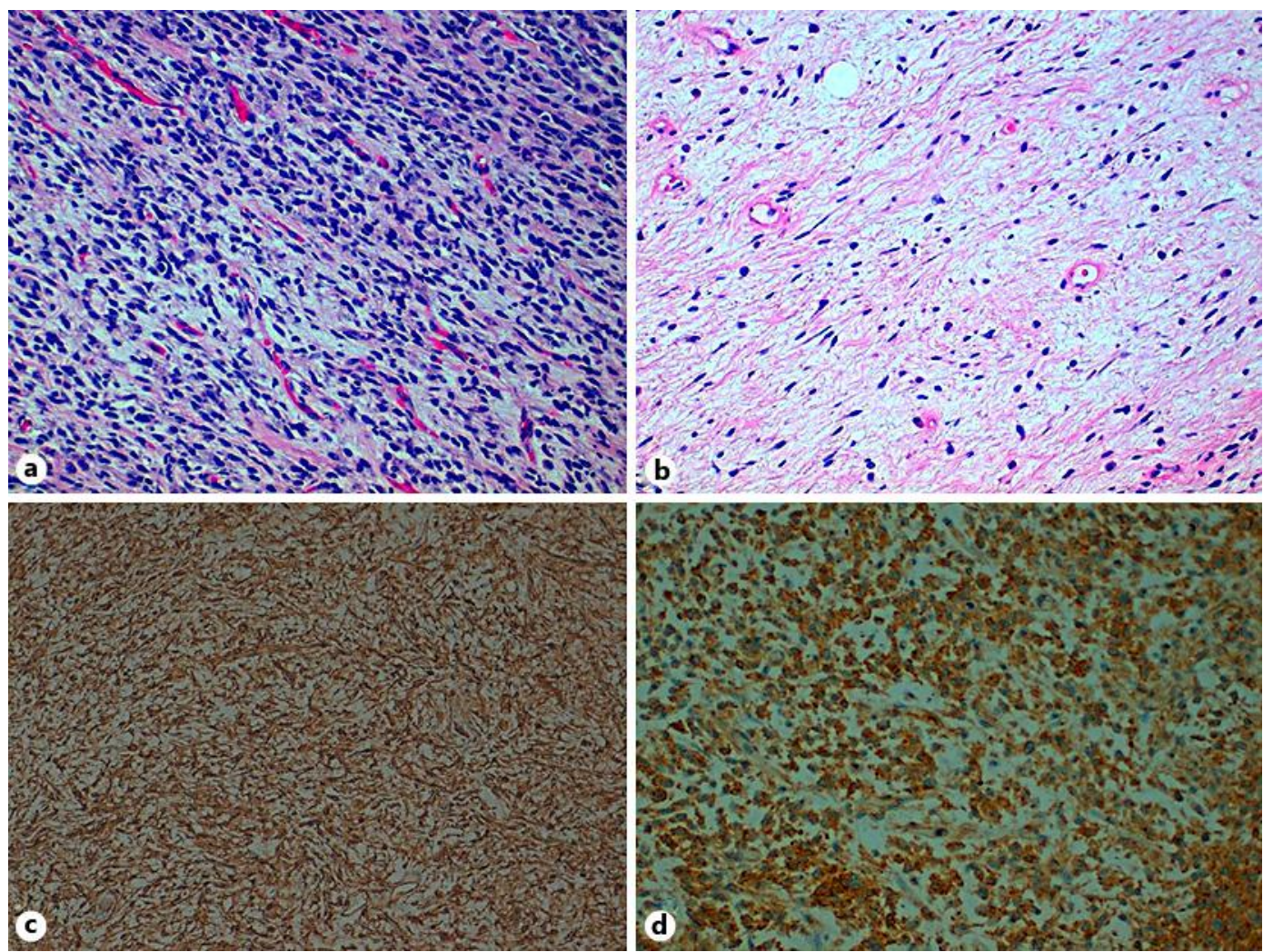

Fig. 3. a Malignant solitary fibrous tumor with heightened cellularity. HE. $\times 20$. $\mathbf{b}$ Tumor containing areas of histologically benign solitary fibrous tumor cells. HE. $\times 20$. c CD34 showing diffuse immunostaining $(\times 10)$. d Positive immunostaining for CD99 $(\times 20)$. 